\title{
Панкреатическая энцефалопатия:
}

\section{клинико-патогенетические и}

\section{Аиагностические аспекты}

\author{
И. В. Аамулинн, ${ }^{1,2}$ А. А. Струценко ${ }^{3}$, П. П. Огурцов ${ }^{3}$, Н. В. Мазурчик \\ 1Первый Московский государственный медицинский университет им. И. М. Сеченова, \\ 2Московский клинический научно-практический центр, \\ ${ }^{3}$ Российский университет Аружбы народов, Москва, Россия
}

Ключевые слова: панкреатическая энцефалопатия, патогенез, клиника, Аифференциальная Аиагностика, прогноз

Синдром панкреатической энцефалопатии (ПЭ) впервые описан N.O. Rothermich и Е. Von Haam в 1941 г. [1, 23]. ПЭ характеризируется разнообразной очаговой неврологической симптоматикой и, в ряде случаев, довольно быстрым развитием деменции [4]. ПЭ считается довольно редким осложнением, развиваясь, по данным ряда авторов, у 9-35\% пациентов с заболеваниями поджелудочной железы (ПЖ) [10]. Наличие ПЭ значительно утяжеляет прогноз острого панкреатита (ОП), повышая летальность до 57\% [20]. Известно, что панкреонекроз, гнойный панкреатит, рецидивирующий панкреатит, атеросклероз сосудов ПЖ часто сопровождаются головной болью, головокружением, расстройством сознания, психомоторным возбуждением, чувствительными расстройствами, вегетативными нарушениями, эпилептиформными припадками, амаврозом и когнитивными нарушениями [18]. Наличие столь разнообразной неврологической симптоматики сложно объяснить только проявлениями общего интоксикационного синдрома и, безусловно, свидетельствует о вовлечении в патологический процесс структур центральной и периферической нервной системы. При поражении ПЖ можно выделить следующие синдромы: неврастенический синдром, острую и хроническую энцефалопатию, остро развившуюся деменцию, часто в сочетании с яркой очаговой симптоматикой, энцефаломиелопатию, полиневропатии [4]. Симптомы ПЭ обычно развиваются в течение первых двух недель, часто - в первые $2-5$ дней от дебюта или обострения ОП вне зависимости от его этиологии $[14,15,22]$. Для ПЭ характерно острое начало, нередко сменяющееся флюктуирующим течением с циклическим прогрессированием, когда периоды ремиссий сменяются эпизодами обострений. В случае стабилизации и/ или благоприятного исхода основного заболевания ПЖ отмечается иногда полный регресс неврологических симптомов, хотя в ряде случаев, особенно у пациентов старшей возрастной группы, даже после разрешения острого заболевания ПЖ может сохраняться стойкий когнитивный и очаговый неврологический дефицит [7].

Причины энцефалопатии при заболеваниях Пж. В настоящее время известно более ста причин развития ОП и, соответственно, ПЭ. Причинами ПЭ в развитых странах чаще всего выступают заболевания желчного пузыря и желчных протоков, сопровождающиеся билиарно-панкреатическим рефлюксом, и алкогольная интоксикация $[1,13]$. Алкоголь и его суррогаты являются причиной развития $35 \%$ случаев ОП в европейской популяции. Симптомами энцефалопатии сопровождаются лекарственные ОП, вызванные приемом ряда психотропных средств, некоторых цитостатиков, антибиотиков и сульфаниламидов [1]. Есть единичные сообщения о развитии ПЭ, причиной которой стал острый ишемический панкреатит, возникший на фоне длительных травматических родов [15]. Фульминантная ПЭ развивается на фоне ОП, вызванного продолжительным голоданием и длительным перитонеальным диализом [17]. Гипертонический криз, тромбоз брыжеечных сосудов, атеросклеротическая окклюзия чревного ствола, расстройства кровообращения после операций при искусственном кровообращении, трансплантации печени, а также шок различной этиологии могут служить причинами ишемического ОП с последующим развитием ПЭ. Тупая или проникающая травма живота с нарушением кровообращения и повреждением паренхимы и протоков ПЖ с выбросом большого количества протеолитических ферментов в окружающие ткани также может привести к развитию ПЭ [1]. Особую роль в развитии ОП, потенциально опасного в отношении развития неврологических осложнений, играет язвенная болезнь двенадцатиперстной кишки при локализации язвенного дефекта на задней стенке, с развитием пенетрации в головку ПЖ $[3,17]$.

Патогенез ПЭ. В развитии ПЭ ведущим механизмом традиционно считается сочетание ферментативной и гормональной дисфункции ПЖ. Выделение в системный кровоток большого количества протео- 
литических ферментов - трипсина, химотрипсина, плазмина, кинина, калликреина, липазы, амилазы и других, обладающих липолитической функцией, оказывает прямое диффузное литическое действие на миелин [2], приводя к распространенной демиелинизации в белом веществе больших полушарий. В случаях ОП на фоне тяжелого эксикоза или длительного голодания возможно развитие фульминантной ПЭ, одним из основных проявлений которой является остро развившаяся деменция. Выявляемые в этих случаях при проведении магнитно-резонансной томографии (MPТ) гиперинтенсивные сигналы в перивентрикулярных областях, подушке таламуса, маммилярных телах и гиппокампе в сочетании с такими симптомами, как острая деменция, поражение глазодвигательных нервов и мозжечковые симптомы, позволяют предположить определенный вклад в патогенез дефицита тиамина и, соответственно, сочетание ПЭ и энцефалопатии Гайе - Вернике [2], что, по данным G. Q. Fey (2012), встречается в 0,8\% случаев всех неалкогольных ОП, обусловленных анорексией, рвотой беременных, послеоперационной рвотой, гемодиализом. Протеолитические ферменты повреждают не только паренхиму головного мозга, но и мозговые оболочки, в которых развивается асептическое воспаление. Кроме того, гиперферментемия в сочетании с дисбалансом инсулина приводит к изменениям водно-электролитного баланса, иногда и углеводного обмена в виде гипо- или гипергликемии. Часто сопровождающие ОП инфекционные осложнения приводят к нарастанию интоксикационного синдрома [15]. Возможно, нейротоксичные агенты образуются при панкреатическом цитолизе, который развивается вследствие нарушения проницаемости мембран ацинарных клеток, приводя к развитию феномена «уклонения» ферментов - инкреции ферментов в кровь непосредственно из ПЖ через мембраны ациноостровковых клеток. Параллельно запускается процесс продукции и высвобождения цитокинов, хемокинов и других медиаторов воспаления $[1,13,23]$, что приводит к увеличению проницаемости сосудистой стенки, миграции лейкоцитов, локальному повреждению тканей и генерализации воспалительной реакции. Это, в итоге, приводит к дополнительному, помимо прямого литического действия протеаз, воспалительному и аутоиммунному повреждению структур как центральной, так и периферической нервной системы. В основе психических нарушений, возможно, лежит прямое или опосредованное влияние цитокинов на нейротрансмиттерные механизмы, рецепторы глюкокортикоидов и серотонина 1А. Эндотоксин и индуцированные им цитокины обладают способностью инициировать синтез цитокин-индуцибельной синтазы оксида азота (NO) с последующей продукцией NO. Избыток NO приводит к ингибированию митохондриальных ферментов, и, соответственно, нейрональному энергетическому дефициту, стимулирующему процессы апоптоза. Несомненно, что помимо цитокинов, трипсин, липаза, фосфолипаза A2 (PLA2) и другие протеолитические ферменты проникают через гематоэнцефалический барьер (ГЭБ) в случае ОП [15]. Некоторые
PLA2 (липопротеин-ассоциированные фосфолипазы) обладают определенным нейротропизмом, непосредственно повреждая фосфолипидные слои мембраны нейронов, что провоцирует цитотоксический отек клеток головного мозга и их демиелинизацию, препятствует нормальному высвобождению ацетилхолина из пресинаптических мембран $[12,15,21]$. Повреждение ГЭБ, помимо всего прочего, приводит к проникновению в паренхиму мозга сенсибилизированных Т-лимфоцитов, что является дополнительным механизмом демиелинизации [24]. Повышение концентрации провоспалительных цитокинов - фактора некроза опухоли (ФНО) $\alpha$, интерлейкина (ИЛ) 1b и ИЛ-6 дополнительно стимулирует проницаемость ГЭБ и, соответственно, еще больше облегчает проникновение в ткани мозга протеаз и других эндотоксинов [12]. В эксперименте было показано, что избыток ФНО- $\alpha$ и ИЛ-1b в крови не только повреждает ткани центральной нервной системы, но и, стимулируя воспалительные изменения в ацинарных клетках, педалирует развитие панкреатита, замыкая, таким образом, один из порочных кругов. Избыток ФНО также приводит к активации PLA2, стимулирующей, во-первых, активацию и адгезию лейкоцитов к эндотелиоцитам, что, в свою очередь, приводит к повреждению эндотелия и повышению проницаемости капиллярной стенки, во-вторых, стимуляции фактора активации тромбоцитов, и, соответственно, агрегации тромбоцитов, вызывая многочисленные капилляротромбозы. Кроме того, индукция лейкоцитарной активности приводит к прямому повреждению миелиновых оболочек. Интересно, что активация PLA2 запускает еще ряд повреждающих механизмов, во-первых, ингибируя высвобождение периферического ацетилхолина, и, таким образом, нарушая нормальную нервно-мышечную передачу, во-вторых, повышение концентрации PLA2 в крови приводит к уменьшению выработки сурфактанта, что приводит к увеличению легочного альвеолярного поверхностного натяжения и уменьшению эластичности легких. Кроме того, протеолитические ферменты непосредственно повреждают паренхиму легких в виде потери сурфактанта, формирования базальных ателектазов и плеврального выпота, приводя к отеку легких и паренхиматозной острой дыхательной недостаточности, катастрофично усугубляющей ишемическое повреждение головного мозга. Действительно, в исследованиях было показано, что у 58\% пациентов с тяжелым ОП в течение первых 48 часов развивается выраженная артериальная гипоксемия. Системная гипоксемия при ОП нарастает из-за гиповолемии, развивающейся по ряду причин, в том числе вследствие многократной рвоты, экссудации жидкости в ткани ПЖ, миграции жидкости в «третье пространство» кишечника. Сгущение крови настолько характерно для ПЭ, что может служить дифференциально-диагностическим признаком. Кроме того, нарушения церебральной микроциркуляции нарастают не только вследствие изменений реологических и электролитных свойств крови, но и вследствие такого осложнения ОП, как легочная жировая эмболия [5]. 
Гипоксия усугубляет и ишемическое повреждение ПЖ, приводя к дополнительному массированному выбросу в кровоток провоспалительных цитокинов, и, в первую очередь, ФНО, обладающего не только нейротоксичным, но и кардиотоксичным действием, снижая сократимость миокарда, что, уже в свою очередь, приводит к нарастанию гипоксии, замыкая очередной порочный круг. Кроме диффузных, выявляются и локальные повреждения головного мозга, к которым в случае ОП приводят не только геморрагии и локальная демиелинизация, но и жировая эмболия, осложняющая ОП, что также подтверждается данными МРТ [20]. Определенную роль в патогенезе ПЭ играют изменения метаболизма глюкозы, связанные с воздействием ряда факторов, в том числе вторичной гепатоцеллюлярной недостаточности. Во-первых, из-за массивного некроза гепатоцитов происходит снижение глюкогенной функции печени, во-вторых, из-за нарушения клиренса инсулина в печени у больных развивается гиперинсулинемия и, как следствие, усугубляется гипогликемия, оказывающая дополнительное повреждающее действие на структуры головного мозга. Панкреонекроз, приводящий к гибели островковых клеток и, соответственно, резкому снижению уровня инсулина, напротив, провоцирует гипергликемию, нарастание периферической инсулинорезистентности и лактатацидоз [1, 2, 5, 10]. Снижается активность пируватдегидрогеназы, способствующей переходу пировиноградной кислоты в ацетилкоэнзим А. Тормозится ресинтез лактата в гликоген. Метаболический ацидоз провоцирует гипервентиляционные нарушения, развивается респираторный алкалоз, приводящий, в свою очередь, к повышению проницаемости ГЭБ и усугублению электролитных нарушений, в том числе в виде гипокалиемии. Снижение концентрации внеклеточного калия приводит к выходу калия из клетки и развитию внеклеточного алкалоза, что дополнительно повышает проницаемость ГЭБ для нейротоксичных агентов. Патогенез психических расстройств, существенно утяжеляющих прогноз при ПЭ, достаточно сложен и в значительной степени остается неясным. В эксперименте при индуцированном ОП в префронтальной коре, полосатом теле, гиппокампе, фронтотемпоральном дофаминергическом пути и мозжечке отмечаются изменения обмена катехоламинов, в первую очередь, повышение концентрации дофамина, снижение концентрации моноаминоксидазы А и тирозингидроксилазы, что было показано при помощи высокоэффективной жидкостной хроматографии $[5,7,20]$.

Патоморфологические изменения при ПЭ. K. Istvan (1929) принадлежит первое клинико-анатомическое описание случая, когда у больного ОП наблюдались общемозговые симптомы, психомоторное возбуждение, менингеальный синдром и клонико-тонические судороги, купировать которые не удалось. Спустя сутки он умер при явлениях нарастающей комы. На аутопсии был обнаружен выраженный отек и набухание головного мозга с наличием очагов деструкции в области лентикулярных ядер и очаги некроза в поджелудочной железе. R. Johnson и Z. Tong описали жировую эмболию мозговых артерий у больного, погибшего от ПЭ, сопровождающейся демиелинизацией [11]. Макроскопически в головном и спинном мозге больных, умерших от панкреатита, выявляются довольно неспецифичные изменения в виде выраженной атрофии коры и подкорковых образований больших полушарий и, нередко, мозжечка, грубого отека мозгового вещества, полнокровия сосудов венозного русла в сочетании с неравномерностью кровенаполнения артериально-капиллярного русла, очагов некроза коры головного мозга, обширных зон демиелинизации в области полуовального центра и диффузных кровоизлияний в белое вещество мозга $[6,7,10]$. Микроскопически определяются выраженные изменения сосудистого звена в виде плазморрагий и диапедезных кровоизлияний в пространства Вирхова - Робина и, в меньшей степени, белое вещество головного мозга, десквамация и дистрофия клеток эндотелия, набухание адвентициальной оболочки, сладж форменных элементов крови, плазматическое пропитывание и сегментарный некроз сосудистой стенки с преимущественным вовлечением артерий среднего и мелкого калибра. Изменения нейронов заключаются в остром набухании, хроматолизе и цитолизе - в сочетании с деструкцией миелиновой оболочки. При этом, несмотря на выявляемую на секции диффузную демиелинизацию белого вещества в сочетании с локальными геморрагическими некрозами, проведение прижизненной MPТ у этих пациентов часто не обнаруживает изменений. Выявляется сателлитоз (пролиферация перинейрональных олигодендроцитов), сморщивание нейронов с избыточным содержанием липофусцина, пролиферативно-дистрофические реакции глии не только головного, но спинного мозга, преимущественно в нижнегрудном и верхнепоясничном отделах. В литературе встречаются описания результатов аутопсий, при которых макроскопически на фоне диффузных атрофических изменений выявляют пятнистые повреждения белого вещества больших полушарий, ствола мозга и мозжечка. Гистохимически в этих участках демиелинизации был выявлен повышенный уровень протеаз (на фоне высокой гиперферментемии), и, в первую очередь, липазы, жировая эмболия церебральных сосудов и, микроскопически, участки цитостеатонекроза $[6,7,10$, 17, 25]. Остро развивающийся амавроз по данным аутопсии является следствием острого демиелинизирующего процесса в зрительном нерве и/или острой геморрагической ретинопатии $[1,5]$.

Клинические особенности и диагностика ПЭ. Наличие ПЭ следует заподозрить, если у пациентов с симптомами ОП, а именно опоясывающей болью в верхних отделах живота, тошнотой, рвотой, лихорадкой, диареей и повышением уровня амилазы в крови и моче выявляются неврологические симптомы [3]. Острая ПЭ, как правило, начинается внезапно, часто с развития психомоторного возбуждения: пациенты мечутся в постели, принимают неестественные позы, пытаются встать, идти, одеться или раздеться, бежать, и т. д. Отмечается дезориентация в месте и времени, зрительная агнозия, в том числе на 
лица, зрительные и слуховые галлюцинации, помрачение сознания [22]. Пароксизмы возбуждения сменяются адинамией, сонливостью, уровень сознания снижается вплоть до комы с развитием децеребрационных и декортикационных поз, что является плохим прогностическим признаком для жизни пациента. Если у пациента развивается острая, подчас необратимая деменция, то, возможно, в данном случае происходит наслоение ПЭ на энцефалопатию Гайе Вернике [16, 25]. В большинстве случаев отмечается сочетание психомоторного возбуждения с развитием синдрома раздражения мозговых оболочек в виде распирающей головной боли, рвоты, светобоязни и менингеальных симптомов, чаще - симптома Кернига, среднего и нижнего симптомов Брудзинского. Иногда первым проявлением ПЭ служит судорожный синдром в виде клонических, тонико-клонических или тонических судорог, что традиционно рассматривается как проявление выраженной общей интоксикации. К психическим и общемозговым симптомам, как правило, хотя и не всегда, присоединяется обширная и разнообразная очаговая неврологическая симптоматика в виде дизартрии, таких корковых симптомов, как афазия, нарушение праксиса, симптомы корсаковской амнезии. У ряда пациентов развивается острый амавроз как проявление острого демиелинизирующего ретробульбарного неврита или/и острой геморрагической ретинопатии, горизонтальный или вертикальный нистагм, мозжечковая атаксия. Со стороны двигательной системы могут выявляться негрубые симптомы в виде преходящих нарушений мышечного тонуса, гипер- и анизорефлексии, выпадения брюшных и подошвенных рефлексов, непостоянных кистевых и стопных (Бабинского, Оппенгейма, Гордона) патологических рефлексов. Изредка развиваются парезы, чаще нижних конечностей, со снижением силы до 3-4 баллов [6, 7, 9, 10, 24]. Довольно часто при ПЭ развиваются миоклонии в мускулатуре дистальных отделов конечностей. Кроме того, встречаются описания гиперкинезов, в частности астерикса [18]. У ряда пациентов отмечаются признаки поражения периферической нервной системы в виде болезненности нервных стволов и периферических расстройств чувствительности. Течение острой ПЭ носит цикличный, флюктуирующий характер, когда выраженность неврологической симптоматики может колебаться в течение нескольких часов или дней, иногда недель, находясь в прямой зависимости от панкреатического процесса $[14,22]$. Традиционно считается, что в случае разрешения ОП происходит практически полный регресс неврологической симптоматики [21]. Действительно, у пациентов в возрасте до 40 лет при правильном и своевременном лечении основного заболевания в подавляющем большинстве случаев отмечается полный регресс неврологической симптоматики. У выживших пациентов старше 60 лет, особенно с отягощенным сосудистым анамнезом, как правило, остается резидуальная неврологическая симптоматика в виде когнитивных расстройств, в том числе обусловленных лобной дисфункцией (апатия, потеря интереса к окружающему, нарушение беглости речи) [22, 24]. Риск резидуальной симптоматики, особенно когнитивных нарушений, повышается при повторении эпизодов острой ПЭ [22]. Летальность при острой ПЭ довольно высока (до 57\%) и обусловлена шоком, геморрагическими осложнениями, кетоацидозом, жировой эмболией церебральных сосудов [7, 12, 19], почечной недостаточностью. Хроническая ПЭ, также отличающаяся флюктуирующим течением с циклическим прогрессированием, формируется на фоне длительно текущего ХП, сопровождающегося ферментной панкреатической декомпенсацией. У пациентов наблюдаются головная боль и небольшие очаговые нарушения в виде поражения двигательных краниальных нервов, повышения сухожильных рефлексов, анизорефлексии, пластической гипертонии мышц и других признаков пирамидной и экстрапирамидной недостаточности. Изредка встречаются эпилептические припадки. У пациентов старшей возрастной группы, особенно с длительным алкогольным анамнезом, постепенно формируется когнитивный дефект в сочетании с очаговой симптоматикой [7]. Неврастенический синдром чаще сопровождает ХП и характеризуется относительно скудной клинической симптоматикой. Головные боли, расстройства сна, общая астенизация, эмоциональная лабильность, снижение внимания в сочетании с умеренными вегетативными симптомами в виде тахикардии, акрогипергидроза, лабильности артериального давления могут затенять, иногда довольно длительно, абортивно выраженные проявления ХП [22]. При этом динамика неврастенических проявлений напрямую зависит от течения ХП, и при благоприятных результатах лечения ХП симптоматика полностью регрессирует.

Диагноз и дифференциальный диагноз. Неврологические проявления ПЭ, особенно при стертости абдоминальных симптомов, могут привлекать к себе основное внимание врачей и тем самым затруднять своевременное распознавание заболеваний ПЖ, требующих проведения комплекса экстренных лечебных мероприятий (вплоть до оперативного вмешательства). Превалирование оболочечных и очаговых симптомов, эпилептиформных изменений делает необходимым проведение дифференциальной диагностики с субарахноидальным кровоизлиянием, менингитом и менингоэнцефалитом, лейкоэнцефалитом Шильдера и рядом других заболеваний. Психомоторное возбуждение, менингеальные симптомы, эпилептиформные приступы сохраняются всего несколько дней и исчезают по мере купирования панкреатической дисфункции. Заподозрить вторичность неврологических симптомов по отношению к страданию ПЖ позволяют, помимо специфических соматических жалоб и данных анамнеза, изменения лабораторных показателей в виде иногда многократного повышения уровня амилазы и липазы в крови и моче. у ряда пациентов выявляется повышение уровня трансаминаз и билирубина, что свидетельствует о вовлечении в патологический процесс и гепатобилиарной системы. При тяжелом течении ПЭ нередко отмечается повышение ликворного давления и уровня белка за счет бета-2-микроглобулина и основного 
белка миелина и мононуклеарный плеоцитоз до 10-50 клеток, в ликворе выявляется липаза [21]. Существенную помощь в диагностике, особенно при стертости абдоминальных симптомов, может оказать визуализация органов брюшной полости. Нейровизуализация играет существенную роль при диагностике ПЭ, при этом предпочтительным методом является MPT, особенно во FLAIR-режиме [14], позволяя выявить типичное для ПЭ грубое диффузное двустороннее поражение белого вещества глубинных отделов, особенно в задних отделах полушарий головного мозга, в сочетании с церебральной атрофией, диффузными изменениями белого вещества моста и ножек мозжечка. По мере улучшения состояния больных выраженность диффузных изменений белого вещества также уменьшается [14]. МРТ позволяет, с чувствительностью 53\% и специфичностью 93\%, выявить энцефалопатию Гайе - Вернике, нередко встречающуюся при ОП. При энцефалопатии Гайе Вернике выявляются очаги в перивентрикулярных отделах межуточного мозга, верхних отделах червя мозжечка, сосцевидных телах. Ряд авторов указывают на частичную нормализацию данных МРТ после разрешения ОП и редукции симптомов ПЭ [14]. Достаточно интересны результаты магнитно-резонансной ангиографии при острой ПЭ, показывающие повышенную извитость и неравномерность диаметра церебральных артерий. Электроэнцефалограмма не является информативной методикой для диагностики ПЭ, так как выявляемые изменения в виде отсутствия либо неравномерности амплитуды альфа-ритма, полиморфных медленных волн, как правило, без признаков латерализации, встречаются и при других метаболических энцефалопатиях. Однако, несмотря на свою неспецифичность, электроэнцефалограмма может использоваться для оценки динамики течения ПЭ. При разрешении абдоминального процесса, как правило, происходит нормализация электрической активности мозга [2, 9]. Проведение нейропсихологического исследования при острой ПЭ бывает существенно затруднено вследствие поведенческих и психических расстройств, а также снижения уровня сознания у пациентов. В то же время, по данным ряда авторов, повторные нейропсихологические исследования при помощи шкалы MMSE, проведенные у одних и тех же пациентов после рецидивов ОП, выявляли достоверное ухудшение когнитивных функций [26]. Вызванные потенциалы (ВП), в том

\section{Аитература:}

1. Агапов К. В. Аиагностика и лечение панкреонекроза. Экономическое обоснование рациональной хирургической тактики : Аис. на соиск. ученой степени А-ра мед. наук / К. В. Агапов. - М., 2012.

2. Алешина Е. А. Когнитивный вызванный потенциал Р300: методика, опыт применения, клиническое значение / Е. А. Алешина, Н. Н. Коберская, И. В. Аамумин // Журнал неврологии и психиатрии им. С. С. Корсакова. - 2009. - № 109 (8). - С. 77-84.

3. Савельев В. С. Острый панкреатит / В. С. Савельев, М. И. Филимонов, С. З. Бурневич // Клиниче- числе вызванный моторный потенциал, изменяются при фактически любом варианте метаболической энцефалопатии. При исследовании коротколатентных слуховых ВП выявляется увеличение латенции III пика, увеличение межпикового интервала и полифазность IV-V и III-V пиков. Соматосенсорные ВП также демонстрируют увеличение латентности у ряда пациентов, моторный вызванный потенциал - увеличение времени центрального проведения [9]. P300, традиционно считающийся чувствительным методом для диагностики когнитивных нарушений [2], выявляет, что при ПЭ амплитуда Р300 снижается в переднеацентральных и центральных областях коры, а латентность Р300 увеличивается в 37-44\% случаев. Эти данные перекликаются с результатами, полученными у пациентов с циррозом печени. Причем в 40\% случаев изменения Р300 выявлялись у пациентов без клинических проявлений ПЭ и без когнитивных нарушений, выявляемых при помощи психометрических тестов [2]. Следует отметить, что существенную помощь в диагностике энцефалопатий, развивающихся на фоне соматических заболеваний, может оказать функциональная нейровизуализация, в частности, позитронная эмиссионная томография. Например, у пациентов с ПЭ позитронная эмиссионная томография показывает увеличение утилизации глюкозы в базальных ганглиях, гиппокампе и мозжечке, что согласуется с такими клиническими проявлениями ПЭ на ранних стадиях, как дефицит внимания, нарушения зрительно-пространственной ориентации, конструктивного праксиса, координации и темпа движений [15].

Заключение. ПЭ является грозным осложнением ОП, существенно утяжеляя его течение и повышая летальность при ОП. Поэтому чрезвычайно актуальной становится разработка диагностического алгоритма ПЭ, позволяющая максимально рано, возможно на доклинической стадии, выявить данное осложнение ОП на максимально ранних стадиях, а, возможно, и предикторы развития ПЭ, что, безусловно, позволит как можно раньше назначить патогенетическую терапию. Вероятно, данный диагностический алгоритм должен включать в себя не только хорошо известные клинические и лабораторные тесты, но и ряд параклинических и нейровизуализационных методик, включая методы функциональной нейровизуализации.

ская хирургия. Национальное руководство / Под реА. В. С. Савельева, А. И. Кириенко. - М. : ГЭОТАР-Медиа, 2009. - T. II. - 832 C.

4. Соматоневрология. Руководство Аля врачей / Под ред. А. А. Скоромца. -М. : Спец/ит, 2009. - 655 с.

5. Acute pancreatitis due to erythromycin overdose / M. S. Tenenbein, M. Tenenbein // Pediatr. Emerg. Care. 2005. - Vol. 21. - P. 675-676.

6. Akwe J. A. Pancreatic encephalopathy / J. A. Akwe, G. E. Westney, T. S. Fongeh // The Amer. J. Case Report. 2008. - Vol. 9. - P. 399-403. 
7. Akwe J. A. Pancreatic encephalopathy / J. A. Akwe, G. E. Westney, T. S Fongeh // Am. J. Case Rep. - 2008. Vol. 9. - P. 399-400.

8. A case of indometacin-induced acute hepatitis developing into chronic autoimmune hepatitis / C. Abraham, J. Hart, S. M. Locke, A. L. Baker // Nature Clinical Practice Gastroenterology \& Hepatology. - 2008. - Vol. 5. P. 172-176.

9. Hollerbach S. Auditory event-related cerebral potentials (P300) in hepatic encephalopathy-topographic distribution and correlation with clinical and psychometric assessment / S. Hollerbach, F. Kullmann, R. Fründ // Hepatogastroenterol. - 1997. - Vol. 44, No 16. P. 1002-1012.

10. Jin S. L. 13 cases of severe acute pancreatitis complicated with pancreatic encephalopathy / S. L. Jin, X. W. Song, H. G. Gu // Shijie Huaren Xiaohua Zazhi. 2000. - Vol. 8. - P. 721-722.

11. Johnson D. A. Pancreatic encephalopathy / D. A. Johnson, N. T. Tong // South Med. J. - 1977. Vol. 70. - P. 165-167.

12. Mechanisms of acinar cell injury in acute pancreatitis / M. G. Raraty, J. A. Murphy, E. Mcloughlin [et al.] // Scand. J. Surg. - 2005. - Vol. 94. - P. 89-96.

13. Neoptolemos J. P. Fast facts: diseases of the pancreas and biliary tract / J. P. Neoptolemos, M. S. Bhutani. - Oxford : Health press, 2006. - 128 p.

14. Ohkubo T. Severe diffuse white matter lesions in a patient with pancreatic encephalopathy / T. Ohkubo, T. Shiojiri, T. Matsunaga // J. Neurol. - 2004. - Vol. 251. P. 476-478.

15. Page postpartum pancreatic encephalopathy a rare case / O. P. Lekhra, A. Maheshwari, Y. Rathore, S. Athale // J. Dental Med. Sci. - 2013. - Vol. 6, No 2. P. 41-43.

16. Pancreatic encephalopathy and Wernicke encephalopathy in association with acute pancreatitis: a clinical study / G. H. Sun, Y. S. Yang, Q. S. Liu [et al.] // World J. Gastroenterol. - 2006. - Vol. 12. P. 4224-4227.

УАK 616.37-002.2-06:616.831]-036-036.22-056.7

\section{$\mathrm{RU}$ Панкреатическая энцефалопатия: киинико-патогенетические и диагностические аспекты}

\author{
И. В. Аамулин ${ }^{1,2}$, А. А. Струценко ${ }^{3}$ П. П. Огурцов ${ }^{3}$, \\ Н. В. Мазурчик ${ }^{3}$ \\ ${ }^{1}$ Первый Московский государственный медицинский \\ университет им. И. М. Сеченова, \\ 2Московский клинический научно-практический центр, \\ ${ }^{3}$ Российский университет Аружбы народов, \\ Москва, Россия
}

Киючевые слова: панкреатическая энцефалопатия, патогенез, кииника, Аифференциальная Аиагностика, прогноз

Панкреатическая энцефалопатия встречается у 9-35\% пациентов с заболеваниями поджелудочной железы и
17. Pancreatic encephalopathy: about 2 cases and review of the literature / N. Doghmi, A. Benakrout, A. Meskine [et al.] // Pan. Afr. Med. J. - 2016. - Vol. 25. P. 147.

18. Pancreatic encephalopathy: an unusual cause of asterixis / V. Sharma, R. Sharma, S. S. Rana, D. K. Bhasin // J. Pancreas (Online). - 2014. - Vol. 15, No 4. P. 383-384.

19. Pandol S. J. Acute pancreatitis / S. J. Pandol // Curr. Opin. Gastroenterol. - 2005. - Vol. 21. - P. 538543.

20. QT interval analysis in patients with acute biliary pancreatitis / F. Kosar, F. Ates, I. Sahin [et al.] // Pancreas. - 2005. - Vol. 31. - P. 238-241.

21. Ramanathan R. S. Necrotizing pancreatitis leading to pancreatic encephalopathy in a patient undergoing long-term continuous ambulatory peritoneal dialysis / R. S. Ramanathan, T. Ahluwalia // J. Acad. Med. Sci. - 2012. - Vol. 2, No 2. - P. 85-87.

22. Ruggieri R. M. Pancreatic encephalopathy: a 7-year follow-up case report and review of the literature / R. M. Ruggieri, L. Lupo, F. Piccoli // Neurol. Sci. - 2002. Vol. 23. - P. 203-205.

23. Serum metabolic signature of minimal hepatic encephalopathy by (1)H-nuclear magnetic resonance / B. Jiménez, C. Montoliu, D. A. Maclntyre [et al.] // J. Proteome Res. - 2010. - Vol. 9, No 10. - P. 51805187.

24. Sharf B. Pancreatic encephalopathy / B. Sharf, E. Bental // J. Neurol. Neurosurg. - Psychiatry. - 1971. Vol. 34. - P. 357-361.

25. Wernicke encephalopathy presenting in a patient with severe acute pancreatitis / A. C. Arana-Guajardo, C. R. Cámara-Lemarroy, E. J. RendónRamírez [et al.] // J. Pancreas. - 2012. - Vol. 13, No 1. - P. 104-107.

26. Zhang X.-P. Pathogenesis of pancreatic encephalopathy in severe acute pancreatitis / X.-P. Zhang, H. Tian // Hepatobiliary Pancreat. Dis. Int. - 2007. - Vol. 6. P. 134-140. характеризируется разнообразной очаговой неврологической симптоматикой. Психоневрологические расстройства наблюдаются как во время обострения, так и в матентный период заболеваний поджелудочной жемезы. Наличие панкреатической энцефалопатии следует заподозрить, если у пациентов с симптомами острого панкреатита выявляются неврологические симптомы. Течение острой панкреатической энцефалопатии носит цикличный, флюктуирующий характер, находясь в прямой зависимости от панкреатического процесса. В развитии панкреатической энцефалопатии ведущим механизмом считается сочетание гиперферментемии с Аисбалансом инсулина, которое приводит к изменениям водно-электролитного баланса и углеводного обмена. Часто сопровождающие острый панкреатит инфекционные осложнения приводят к нарастанию интоксикационного синарома. 


\section{UA Панкреатична енцефалопатія: киініко-патогенетичні та діагностичні аспекти}

\author{
I. В. Аамулін ${ }^{1,2}$, А. А. Струценко ${ }^{3}$, П. П. Огурцов ${ }^{3}$, \\ Н. В. Мазурчик ${ }^{3}$ \\ ${ }^{1}$ Перший Московський Аержавний медичний універ- \\ ситет ім. І. М. Сєченова, \\ ${ }^{2}$ Московський клінічний науково-практичний центр, \\ ${ }^{3}$ Російський університет Аружби народів, \\ Москва, Росія
}

Ключові слова: панкреатична енцефалопатія, патогенез, клініка, Аиференційна Аіагностика, прогноз

Панкреатична енцефалопатія зустрічається у 9-35\% пацієнтів із захворюваннями підшлункової залози і характеризується різноманітною осередковою неврологічною симптоматикою. Психоневрологічні розлади спостерігаються як піА час загострення, так і в латентний період захворювань підшлункової залози. Наявність панкреатичної енцефалопатії сліА запідозрити, якщо у пацієнтів із симптомами гострого панкреатиту вияв^яються неврологічні симптоми. Перебіг гострої панкреатичної енцефалопатії має циклічний, флюктуючий характер, перебуваючи в прямій залежності віА панкреатичного процесу. У розвитку панкреатичної енцефалопатії провіАним механізмом вважається поєАнання гіперферментемії із Аисбалансом інсуліну, що призводить Ао змін воАно-електролітного балансу і вуглеводного обміну. Інфекційні усклаАнення, що часто супроводжують гострий панкреатит, призводять Ао наростання інтоксикаційного синарому.

\section{EN Pancreatic encephalopathy: clinical, pathogenetic and diagnostic aspects}

\author{
I. V. Damulin 1,2 , A. A. Strutsenko ${ }^{3}$, P. P. Ogurtsov ${ }^{3}$, \\ N. V. Mazurchik ${ }^{3}$ \\ ${ }^{1}$ First Moscow State Medical University n. a. I. M. Sechenov, \\ ${ }^{2}$ Moscow Clinical Research and Practical Center, \\ 3Peoples' Friendship University of Russia, \\ Moscow, Russia
}

Key words: pancreatic encephalopathy, pathogenesis, clinical features, differential diagnosis, prognosis

Pancreatic encephalopathy occurs in $9-35 \%$ of patients with pancreatic diseases and is characterized by a variety of focal neurological symptoms. Neuropsychiatric disorders are observed both during the acute and latent period of the pancreatic diseases. The presence of pancreatic encephalopathy should be suspected if patients with symptoms of acute pancreatitis have neurological symptoms. The course of acute pancreatic encephalopathy is cyclical, fluctuating, being in direct proportion to the pancreatic process. Leading mechanism in the development of pancreatic encephalopathy is a combination of hyperenzymemia with insulin imbalance which leads to changes of water-electrolyte balance and carbohydrate metabolism. Infectious complications, that often accompany acute pancreatitis, lead to the increasing intoxication syndrome. 